\title{
Article \\ Diode-Like Current Leakage and Ferroelectric Switching in Silicon SIS Structures with Hafnia-Alumina Nanolaminates
}

\author{
Vladimir P. Popov ${ }^{1, *(\mathbb{D})}$, Fedor V. Tikhonenko ${ }^{1}$, Valentin A. Antonov ${ }^{1}$, Ida E. Tyschenko ${ }^{1} \mathbb{D}$, \\ Andrey V. Miakonkikh ${ }^{2}$ (D), Sergey G. Simakin ${ }^{2}$ and Konstantin V. Rudenko ${ }^{2}$ \\ 1 Rzhanov Institute of Semiconductor Physics SB RAS, 630090 Novosibirsk, Russia; \\ ftikhonenko@gmail.com (F.V.T.); ava@isp.nsc.ru (V.A.A.); tys@isp.nsc.ru (I.E.T.) \\ 2 Valiev Institute of Physics and Technology RAS, 117218 Moscow, Russia; miakonkikh@ftian.ru (A.V.M.); \\ simser@mail.ru (S.G.S.); rudenko@ftian.ru (K.V.R.) \\ * Correspondence: popov@isp.nsc.ru
}

check for updates

Citation: Popov, V.P.; Tikhonenko, F.V.; Antonov, V.A.; Tyschenko, I.E.; Miakonkikh, A.V.; Simakin, S.G.; Rudenko, K.V. Diode-Like Current Leakage and Ferroelectric Switching in Silicon SIS Structures with

Hafnia-Alumina Nanolaminates.

Nanomaterials 2021, 11, 291.

https://doi.org/10.3390/nano11020291

Received: 9 November 2020

Accepted: 18 January 2021

Published: 22 January 2021

Publisher's Note: MDPI stays neutral with regard to jurisdictional claims in published maps and institutional affiliations.

Copyright: (c) 2021 by the authors. Licensee MDPI, Basel, Switzerland. This article is an open access article distributed under the terms and conditions of the Creative Commons Attribution (CC BY) license (https:/ / creativecommons.org/licenses/by/ $4.0 /)$.

\begin{abstract}
Silicon semiconductor-insulator-semiconductor (SIS) structures with high-k dielectrics are a promising new material for photonic and CMOS integrations. The "diode-like" currents through the symmetric atomic layer deposited (ALD) $\mathrm{HfO}_{2} / \mathrm{Al}_{2} \mathrm{O}_{3} / \mathrm{HfO}_{2} \ldots$ nanolayers with a highest rectification coefficient $10^{3}$ are observed and explained by the asymmetry of the upper and lower heterointerfaces formed by bonding and ALD processes. As a result, different spatial charge regions (SCRs) are formed on both insulator sides. The lowest leakages are observed through the stacks, with total $\mathrm{Al}_{2} \mathrm{O}_{3}$ thickness values of $8-10 \mathrm{~nm}$, which also provide a diffusive barrier for hydrogen. The dominant mechanism of electron transport through the built-in insulator at the weak field $\mathrm{E}<1 \mathrm{MV} / \mathrm{cm}$ is thermionic emission. The Poole-Frenkel (PF) mechanism of emission from traps dominates at larger E values. The charge carriers mobility $100-120 \mathrm{~cm}^{2} /(\mathrm{V}$ s) and interface states (IFS) density $1.2 \times 10^{11} \mathrm{~cm}^{-2}$ are obtained for the n-p SIS structures with insulator $\mathrm{HfO}_{2}: \mathrm{Al}_{2} \mathrm{O}_{3}$ (10:1) after rapid thermal annealing (RTA) at $800{ }^{\circ} \mathrm{C}$. The drain current hysteresis of pseudo-metaloxide-semiconductor field effect transistor (MOSFET) with the memory window 1.2-1.3 V at the gate voltage $\left|\mathrm{V}_{\mathrm{g}}\right|< \pm 2.5 \mathrm{~V}$ is maintained in the RTA treatment at $\mathrm{T}=800-900{ }^{\circ} \mathrm{C}$ for these transistors.
\end{abstract}

Keywords: SIS structures; silicon-on-ferroelectric; diode and FET characteristics; leakage mechanisms; ferroelectric hysteresis

\section{Introduction}

Recently, the high energy efficiency of optical switches based on semiconductorinsulator-semiconductor (SIS) structures has been reported, reaching femto- and even attojoules per operation when using a design of hybrid structures based on III-V/Si semiconductor pairs [1-5]. The development of more energy-efficient switches, compared to thermo-optical or MEMS devices, means real progress in the implementation of not only fast intrachip communication with switch frequencies of up to $200 \mathrm{GHz}$ [4-8], but also perspectives in building deep learning artificial neural networks based on ferroelectric transistors (FeFET), optical or quantum gates $[9,10]$ compatible with the industrial CMOS technology. Hybrid III-V/Si structures noticeably increase the complexity of mass production of integral circuits (ICs) by the industrial CMOS silicon technology. Thus, the development of all silicon-based switches is a task of current interest.

One of the options for reducing energy consumption in the CMOS technology is the embedding of ferroelectric materials, which provide the inherent amplification of potentials at semiconductor-ferroelectric (FE) interfaces and reduce losses in FeFET keys. Model calculations have shown that using FE insulators provides the possibility of switching for optical phase shifters in the $\mathrm{GHz}$ frequency range with a rather low phase shift $\mathrm{V}_{\pi} \mathrm{L} \sim 0.1 \mathrm{~V} \mathrm{~cm}$ at bias voltages of $\mathrm{V} \sim 1 \mathrm{~V}$ on a SIS silicon-based structure with a $20 \mathrm{~nm}$ FE $\mathrm{Y}: \mathrm{HfO}_{2}$ nanolayer [11]. The parameter of FE-losses $\rho$ must not exceed $\rho \cong 10 \mathrm{Ohm} \cdot \mathrm{cm}$ for 
these semiconductor-ferroelectric-semiconductor (SFS) structures. The real fabrication of similar structures is possible using direct bonding techniques, but it encounters certain difficulties - the low temperature stability of amorphous FE nanolayers, formation of gas blisters, crystallites, and high interface state density $\mathrm{D}_{\text {it }}$ at the bonded boundary-that reduce the charge carrier mobility in a silicon layer, leading to high leakage currents through the insulator $[1,12]$. The latter challenge can be solved by using a stable wide bandgap amorphous dielectric or a reverse bias for semiconductors with different types of conductivity instead of a direct bias in SIS structures, as has been recently shown [13]. In that case, high charge carrier mobility and low $D_{\text {it }}$ values could be obtained at the interfaces [1].

The other important issues are the lowering of the SIS diode bias voltage and the energy consumption for using these devices in the Internet-of-Things. The well investigated Schottky barrier (SB) FE diodes, where a fully symmetrical metal-ferroelectric-metal (MFM) structure works as a rectifying diode due to the lowering of SB at one MF interface and its increase at the other one due to polarization fields [14-22], are an interesting prospect. However, we did not find in the literature any reports devoted to forming similar FE diodes using homojunction silicon layers in SFS structures. These could provide low-voltage FE diode operation if the well-known dependence of ferroelectric properties on interface boundary conditions did not suppress the polar phase formation [23].

The aim of this work was the investigation of the electrical properties of both SIS and SFS silicon structures formed by direct bonding and the implanted hydrogen transfer of a silicon layer onto a $\mathrm{Si}$ substrate with an $\mathrm{FE}$ stack based on $\mathrm{HfO}_{2} / \mathrm{Al}_{2} \mathrm{O}_{3}$ nanolaminates. Inserting highly thermally stable $\mathrm{Al}_{2} \mathrm{O}_{3}$ layers increases the thermal stability of the ferroelectric properties of SFS structures during subsequent treatments at the CMOS front-end-of-line (FEOL) fabrication processes instead of the low thermal RTA treatment at $450{ }^{\circ} \mathrm{C}$ for $50 \mathrm{~s}$ [24]. The quality of these robust SFS structures with composite ferroelectric layers were characterized by their charge carrier mobility and the density of traps at the interphase boundaries, as well as by determining the current leakage mechanisms in the charge carriers enrichment modes ("direct" branch of the I-V curve), and the depletion mode ("reverse" branch) in the space charge region (SCR).

The outline of this paper is as follows. In Section 2, we explain our SIS and SFS wafer specifications and the fabrication process. The electric characteristic measurements are also briefly reviewed. In Section 3, we discuss our approaches to controlling the leakage and rectification currents in SIS structures using symmetrical or asymmetrical stacks of two different alumina and hafnia $\left(\mathrm{Al}_{2} \mathrm{O}_{3}\right.$ and $\left.\mathrm{HfO}_{2}\right)$ dielectric nanolayers changing their order in stacks but not the full thickness. In Section 4, we briefly discuss the leakage current dominant mechanisms and the hysteresis of transfer characteristics of our SFS pseudo-MOSFET (metal-oxide-semiconductor field effect transistor) structures in more details, because these new structures could potentially find widespread use in artificial intelligence integrated circuits (AI IC) due to their high-quality electronic transport and memory properties. In Section 5, we conclude and discuss the future outlook.

\section{Materials and Methods}

Thin films of stacks and nanolaminates of alumina/hafnia $\left(\mathrm{Al}_{2} \mathrm{O}_{3} / \mathrm{HfO}_{2}\right)$, as well as single $\mathrm{Al}_{2} \mathrm{O}_{3}$ or $\mathrm{HfO}_{2}$ layers, were grown as an insulator for SIS structures by plasmaenhanced atomic layer deposition (PEALD) on (001) silicon wafers. Atomic layer deposition was carried out in the FlexAl tool (OIPT, Yatton, Bristol, UK) using a $13.56 \mathrm{MHz}$ inductively coupled (ICP) plasma source. The $\mathrm{SiO}_{\mathrm{x}} \mathrm{N}_{\mathrm{y}}$ interlayer between silicon and high-k layer was formed by the plasma nitridization of residual native silicon oxide to reduce the density of electrically active defects on the surface. The nitridization at $\mathrm{T}=500{ }^{\circ} \mathrm{C}, \mathrm{N}_{2}$ pressure $p=20 \mathrm{mTorr}$ and ICP discharge power $\mathrm{W}=400 \mathrm{~W}$ during $180 \mathrm{~s}$ were provided in situ immediately before the ALD process at $250-300{ }^{\circ} \mathrm{C}$ in the same chamber. In the alumina deposition process, the trimethylaluminum (TMA) precursor was used as an organometallic precursor, and oxygen plasma as an oxidizing agent. 
The Tetrakis(ethylmethylamido)hafnium(IV) (TEMAH) precursor and also oxygen plasma were used to grow the hafnia film.

SIS structures were formed by the direct bonding technique and hydrogen transfer by the $\mathrm{H}_{2}{ }^{+}$ions $(\mathrm{E}=120 \mathrm{keV})$ implantation into the $\mathrm{Si}$ donor wafer, then by the bonding with Si n- or p-type substrates and by the thermally induced cleavage by SmartCut ${ }^{\circledR}$ or DeleCut methods (See Figure S1, Supplementary Materials). As a result, silicon and insulator layers simultaneously, or only a silicon layer, were transferred on the substrates, respectively [25]. Before the vacuum bonding of the surface of a pair of silicon wafers, they were processed in Radio Frequency (RF) plasma of nitrogen and oxygen for $60 \mathrm{~s}$. The transfer of n-Si layers from (001) $4.5 \mathrm{Ohm} \cdot \mathrm{cm}\left(3-6 \times 10^{14} \mathrm{~cm}^{-3}\right)$ wafers implanted with hydrogen to similar or p-Si (001) $10 \mathrm{Ohm} \cdot \mathrm{cm}\left(1-2 \times 10^{15} \mathrm{~cm}^{-3}\right)$ substrates with a precoated $20 \mathrm{~nm}$ stack or nanolaminates $\mathrm{HfO}_{2} / \mathrm{Al}_{2} \mathrm{O}_{3}$, or single $20 \mathrm{~nm}$ layers of $\mathrm{HfO}_{2}$ and $\mathrm{Al}_{2} \mathrm{O}_{3}$, was carried out by the DeleCut method using the vacuum cleaning and temperature bonding (VCTB) in vacuum at a temperature of $\sim 100{ }^{\circ} \mathrm{C}$ to increase the effective bonding area and to suppress the large stress generation during the followed thermal splitting of hydrogen implanted Si wafer (Figure 1) [25]. Using the implanted hydrogen transfer of only Si layers makes it possible to avoid the defect generation in the high-k stack at the $\mathrm{H}$ implantation and subsequent thermal treatments.

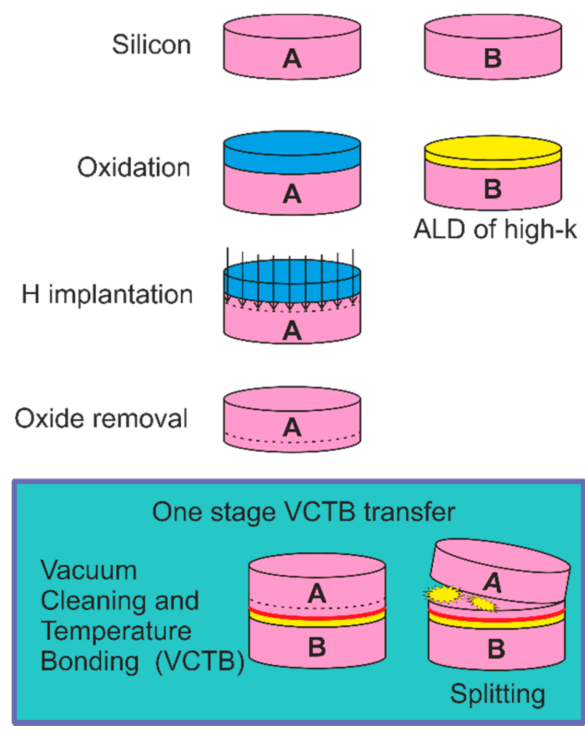

Figure 1. The SFS (semiconductor-ferroelectric-semiconductor) structure process flow (for more data see the $[25,26])$.

The same last procedure was used for the SmartCut ${ }^{\circledR}$ transfer of both silicon and high-k stack layers on the Si substrate instead of the atmospheric bonding and cleavage (Figure S1, Supplementary Materials). The thermal cleavage $\left(\mathrm{T}=450^{\circ} \mathrm{C}\right)$ resulted in the transfer of the layer package of Si/high-k stack on the Si-substrate, or only a Si-layer onto the high-k stack/Si-substrate. These SIS wafers, similar to usual silicon-on-insulator (SOI), with a high-k dielectric instead of silica, were subjected to a sequential furnace or rapid thermal annealing in an atmosphere of argon or nitrogen at temperatures of $650-1100^{\circ} \mathrm{C}$ (furnace annealing and rapid thermal annealing). With respect to the samples, the Si films in the SIS samples were thinned by the sequential operations of chlorine oxidation at the $1100{ }^{\circ} \mathrm{C}$ / wet etching $(\mathrm{O} / \mathrm{E})$ of the oxidized layer in a $1 \% \mathrm{HF}$ solution to the Si layer thicknesses of 50-300 nm.

The C-V and I-V measurements and drain-gate characteristics of pseudo-MOS transistors were used on the lithographically created mesa structures in the upper Si layer sized $1 \times 1 \mathrm{~mm}^{2}$ or in the Corbino geometry in the transferred Si layer of $1 \times 1 \mathrm{~mm}^{2}$ in size. $\mathrm{Al}$ contacts in the Corbino geometry after the post-metallization annealing had a $0.6 \mathrm{~mm}$ 
inner circle, and electrodes with an outer ring diameter of $3 \mathrm{~mm}$ on the transferred silicon layer. The Si layer outside the lithographic masks was removed before measurements in boiling ammonia at $200^{\circ} \mathrm{C}$. The measurements were carried out with the Keythley 4200 unit (Tektronix Inc. of Beaverton, OR, USA) using tungsten probe needles at the distance of $100 \mu \mathrm{m}$ and the tip radius of $20 \mu \mathrm{m}$ with the clamping force of $60 \mathrm{~g}$ as drain and source contacts, and with the back gate, which was the Si-substrate with the ohmic InGa contact. The layer thicknesses of SIS structures were controlled by spectral ellipsometry (SE) after each step of sample fabrication.

\section{Results}

\subsection{Symmetrical SIS with a 20-nm-Thick Alumina or Hafnia Built-In Insulator}

The data in Figures 2-6 present only the last isochronal temperature data, where the slow interface states were essentially removed. These slow interface states provide huge (3-15 V) unstable C-V and I-V hysteresis on these defect states after the thermal treatments in the range $600-800{ }^{\circ} \mathrm{C}$ similar to the flash memory that out the scope of interest. Their removal was controlled by $\mathrm{C}-\mathrm{V}$ and pseudo-MOSFET measurements at different sweeping rates (see e.g., Figures 1, 4 and 8). To minimize the leakage currents through the SIS structure, a 20-nm-thick alumina layer was firstly investigated as an insulator after different thermal treatments due to its high bandgap and amorphous phase stability [26-28].

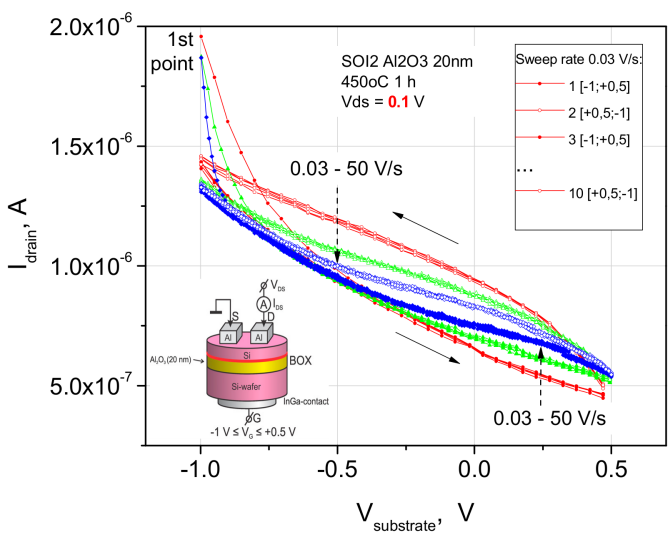

(a)

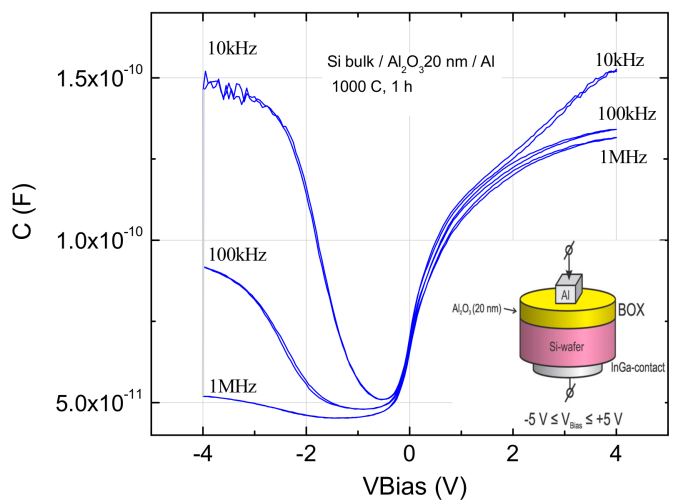

(b)

Figure 2. (a) Hysteresis-like behavior of the drain-gate characteristics at the range $\mathrm{V}_{\mathrm{g}}=-1.0+0.5 \mathrm{~V}$ of n-SIS pseudoMOSFET (metal-oxide-semiconductor field effect transistor) with the $500 \mathrm{~nm} \mathrm{n}-\mathrm{Si} / 20 \mathrm{~nm} \mathrm{Al}{ }_{2} \mathrm{O}_{3} / \mathrm{n}$-Si substrate after the furnace annealing (FA) at $450{ }^{\circ} \mathrm{C}$ during $1 \mathrm{~h}$. Potential $\mathrm{V}_{\mathrm{g}}$ was applied to the $\mathrm{n}$-Si substrate. The drain voltage $\mathrm{V}_{\mathrm{DS}}$ was $0.1 \mathrm{~V}$ for all pseudo-MOSFET measurements. The sweep rate was $50 \mathrm{~V} / \mathrm{s}, 5.0 \times 10^{-1} \mathrm{~V} / \mathrm{s}, 3.3 \times 10^{-3} \mathrm{~V} / \mathrm{s}$ (shown by dashed arrows). In the inset are the measurement scheme and the layers of the n-SIS structure, where the bonding interface is indicated by a red line; (b) C-V plots of the MIS structure with high-k insulator $\mathrm{Al}_{2} \mathrm{O}_{3}$ after the final FA at $1000{ }^{\circ} \mathrm{C}$ for $1 \mathrm{~h}$ and top Si layer etching. In the inset are the measurement scheme and the n-type MIS structure layers.

Figure 2a shows the hysteresis-like drain-gate characteristics of n-SIS pseudo-MOSFETs with a $500 \mathrm{~nm}$ n-Si layer and a $20 \mathrm{~nm}$ insulator layer of an $\mathrm{ALD}^{-1} \mathrm{O}_{3}$ layer immediately after the furnace annealing at $450{ }^{\circ} \mathrm{C}$ for the sweep range of $\mathrm{V}_{\mathrm{g}}=-1.0+0.5$ Volts. The gate voltage $\mathrm{V}_{\mathrm{g}}$ was applied to the $\mathrm{n}-\mathrm{Si}$ substrate, and the sweep rate was varied from $50 \mathrm{~V} / \mathrm{s}$ to $3.3 \times 10^{-3} \mathrm{~V} / \mathrm{s}$. A decrease in the current value with a decrease in the negative bias indicates a hole conductivity and a built-in negative charge in the insulator. The observed hysteresis behavior of I-V is apparently due to the slow interface states (IFS) recharging in the insulator. The charge capture on those levels has a typical dependence on the sweep speed (Figure 2a, dashed arrows). 


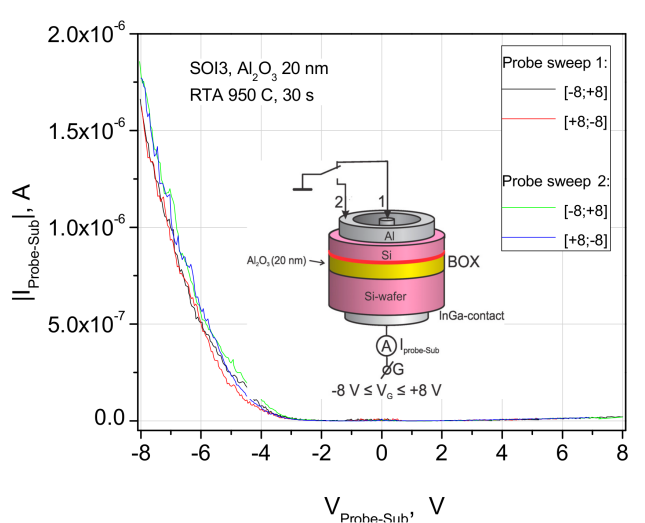

(a)

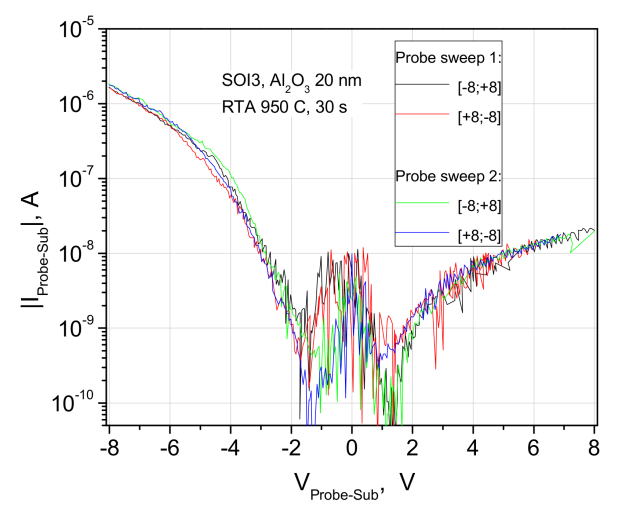

(b)

Figure 3. (a) Diode-like I-V characteristics of the source current-gate voltage (Probe sweep 2) and drain current-gate voltage (Probe sweep 1) contacts of n-SIS pseudo-MOSFETs on the structures $500 \mathrm{~nm} \mathrm{n-Si/20} \mathrm{nm} \mathrm{Al}_{2} \mathrm{O}_{3} / \mathrm{Si}$-substrate after the RTA treatment at $950{ }^{\circ} \mathrm{C}$ for $30 \mathrm{~s}$. The I-V curves are shown for the sweep in the range $\mathrm{V}_{\mathrm{g}}=-8+8 \mathrm{~V}$ on the linear scale; (b) the same on the semi-logarithmic scales.

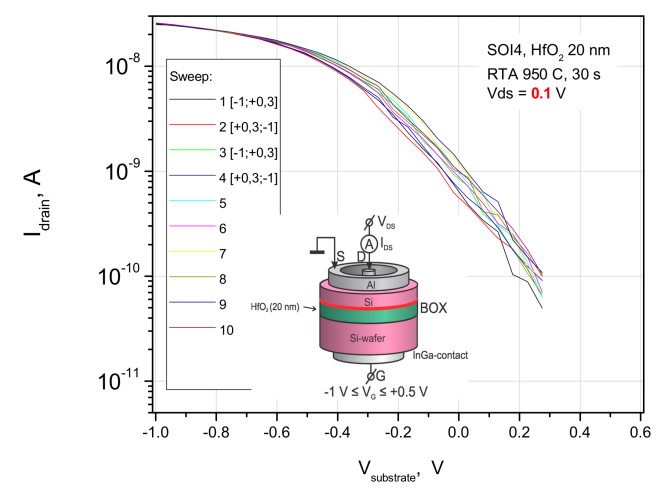

(a)

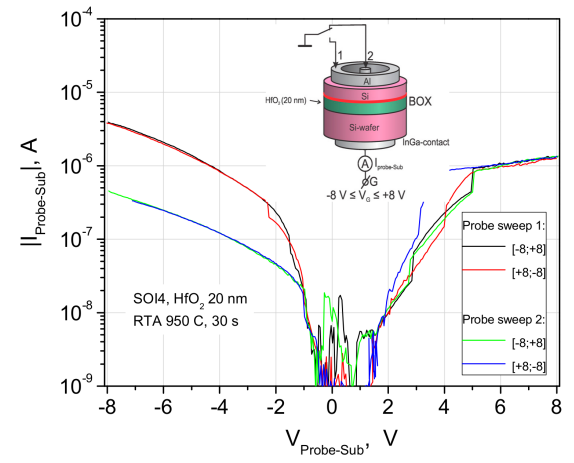

(b)

Figure 4. (a) Drain-current-gate voltage characteristics of the n-SIS (500 nm n-Si/20 nm $\mathrm{HfO}_{2} / \mathrm{Si}$ substrate) pseudo-MOSFETs after the RTA at $950{ }^{\circ} \mathrm{C}$ for a scan of $\mathrm{V}_{\mathrm{g}}=-1.0+0.6 \mathrm{~V} ;(\mathbf{b})$ current-voltage characteristics at the source-gate and drain-gate contacts, bias voltages in the range $\mathrm{V}_{\mathrm{g}}=-8+8 \mathrm{~V}$.

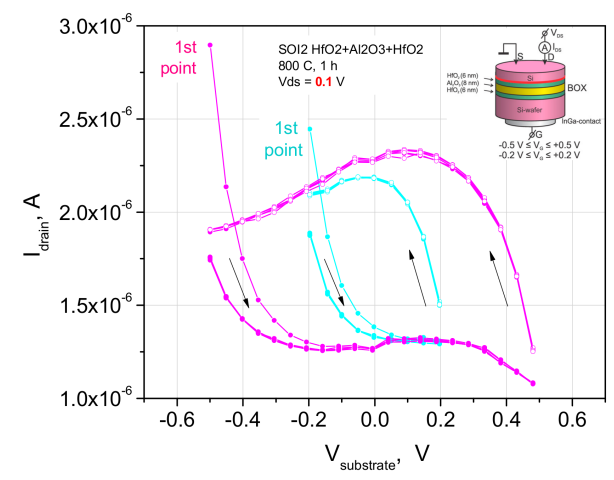

(a)

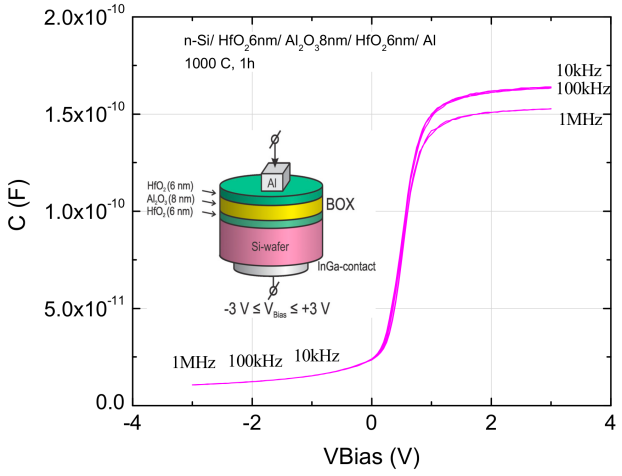

(b)

Figure 5. (a) Hysteresis behavior of the electron current in the transfer characteristics of $n$-SIS pseudo-MOSFETs with the $500 \mathrm{~nm}$ n-Si $/ 20 \mathrm{~nm} \mathrm{HfO} 26 \mathrm{~nm} / \mathrm{Al}_{2} \mathrm{O}_{3} 8 \mathrm{~nm} / \mathrm{HfO}_{2} 6 \mathrm{~nm} / \mathrm{n}$-Si substrate on the mesa structures with tungsten needle-shaped contacts (see inset) after the FA at $800{ }^{\circ} \mathrm{C}$ for $1 \mathrm{~h}$. Constant sweep rate $50 \mathrm{~V} / \mathrm{s}$ in the two ranges of $\mathrm{V}_{\mathrm{g}}=-0.2+0.2 \mathrm{~V}$ (cyan) and $\mathrm{V}_{\mathrm{g}}=-0.5+0.5 \mathrm{~V}$ (magenta) is set for measurements with the starting (1st) point at $\mathrm{V}_{\mathrm{g}}=-0.2$ or $-0.8 \mathrm{~V}$ during multicycle measurements. The gate voltage $\mathrm{V}_{\mathrm{g}}$ is applied to the $\mathrm{n}-\mathrm{Si}$ substrate; $(\mathbf{b}) \mathrm{C}-\mathrm{V}$ plots of the MIS structure with high-k insulator stack $\mathrm{HfO} 2 / \mathrm{Al} 2 \mathrm{O} 3 / \mathrm{HfO} 2$ after the $\mathrm{FA}$ at $1000{ }^{\circ} \mathrm{C}$ for $1 \mathrm{~h}$ and top Si layer etching. In the inset are the measurement scheme and the n-type MIS structure layers. 


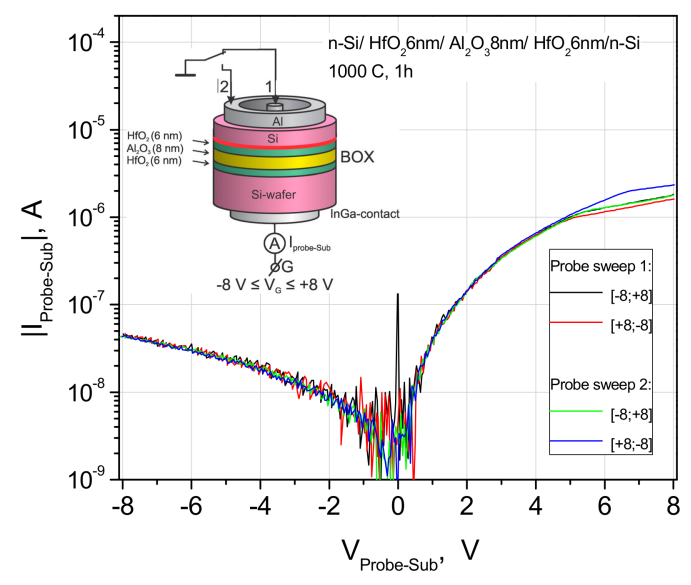

(a)

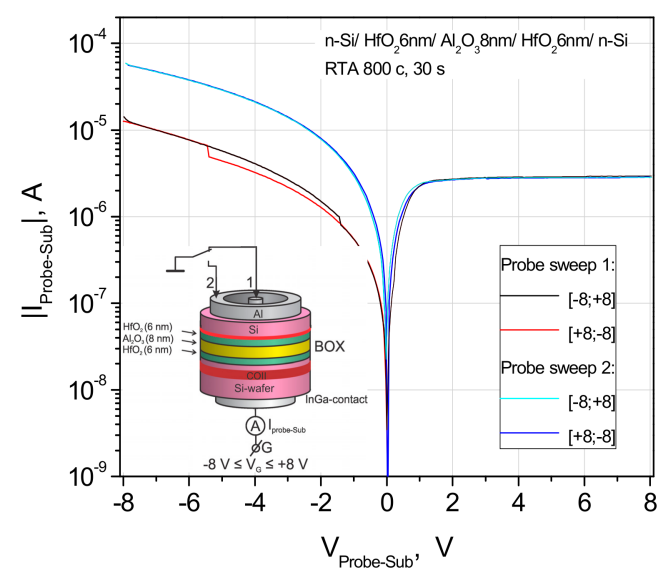

(b)

Figure 6. (a) Diode-like current-voltage (I-V) characteristics at the source-gate contacts and drain-gate contacts of n-SIS Corbino structures on the wafers fabricated by the DeleCut method: $500 \mathrm{~nm}$ n-Si $/ \mathrm{HfO}_{2} 6 \mathrm{~nm} / \mathrm{Al}_{2} \mathrm{O}_{3} 8 \mathrm{~nm} / \mathrm{HfO} 26 \mathrm{~nm} / \mathrm{n}-\mathrm{Si}-$ substrate, after the $\mathrm{FA}$ at $100{ }^{\circ} \mathrm{C}$ for $1 \mathrm{~h}$; (b) the same, but with a $\mathrm{CO}^{+}$implanted getter $\left(\mathrm{E}_{\mathrm{CO}+}=90 \mathrm{keV}, \phi=1 \times 10^{16} \mathrm{~cm}^{-2}\right)$ after the RTA at $800{ }^{\circ} \mathrm{C}$ for $30 \mathrm{~s}$. The bias voltage is applied to the n-Si substrate. In the insets are the measurement scheme and the n-SIS structure layers, where the bonding interface and COII getter are indicated by a red line and stripe, respectively.

A further FA or RTA at the increased temperatures $950-1000{ }^{\circ} \mathrm{C}$ does not lead to a slow IFS removal according to the $\mathrm{C}-\mathrm{V}$ measurements at different frequencies (Figure $2 \mathrm{~b}$ ) or crystallization of amorphous $\mathrm{ALD} \mathrm{Al}_{2} \mathrm{O}_{3}$, but eliminates the residual defects in the transferred silicon film and also leads to the formation of silicon oxide interlayers in the insulator boundaries and to the formation of positively charged oxygen vacancies in aluminum oxide [26,27]. As a result, a large positive charge appears in the $\mathrm{Al}_{2} \mathrm{O}_{3}$ insulator, and the field effect is almost impossible to observe due to the electron accumulation at the insulator boundaries.

Huge changes in the drain current in n-SIS pseudo-MOSFET structures occur when the gate voltage $V_{g}$ changes in the interval from -8 to +8 Volts, even after rapid thermal annealing (RTA), due to leaks through the insulator layer (Figures 3 and 4). The leakage currents were measured with an alternately grounded source or drain contacts. They decrease at bias voltages $\left|V_{\mathrm{g}}\right| \sim 1 \mathrm{~V}$, with respect to $\mathrm{V}_{\mathrm{g}}$ around $0 \mathrm{~V}$, and demonstrate pronounced "diode like" characteristics at $\left|\mathrm{V}_{\mathrm{g}}\right|>2 \mathrm{~V}$. The curves could also be reversed when the location of the probes or mesa structures on the wafer changed. Moreover, the changes in the ratio of leakage currents through the insulator from 1 to 10 were not proportional to the ratio of the source and drain $\mathrm{Al}$ contact areas $\left(\mathrm{A}_{\mathrm{s}}=3.9 \times 10^{-2} \mathrm{~cm}^{2}\right.$, source contact with Probe 1 and $A_{d}=3.0 \times 10^{-3} \mathrm{~cm}^{2}$, drain contact with Probe 2) for the mesa structures with Corbino geometry, which is about 1 in Figure 3. Using these contact areas and $0.6 \mathrm{~mm}$ distance between them we can estimate the defect density.

This behavior indicates the presence of randomly located defect critical density $\mathrm{N}_{R}$ in the insulator layer with a value of $\mathrm{N}_{\mathrm{R}}=1 / \mathrm{A}_{\mathrm{d}}<3.3 \times 10^{2} \mathrm{~cm}^{-2}$, which determines the current flow through the buried dielectric, similar to the phenomena in oxide-based memristors. At voltages $\left|\mathrm{V}_{\mathrm{g}}\right|>1 \mathrm{~V}$, the currents and noises at I-V curves sharply decrease due to the carrier depletion effect in the silicon layers adjacent to the insulator in the SCR on one of the sides, and then the accumulation of electrons or holes on both sides of the dielectric boundaries, and vice versa, when the polarity changes (Figure 3). Probably, accumulation and inversion phenomena can switch currents through the defects in the insulator layer, and they are responsible for the charge carriers transfer if they propagate to one of the insulator boundaries. These defects are similar to those previously observed by TEM grain boundaries [25,27], or lonely conducting filaments and behave like ohmic shunts; the current through these defects increases linearly with $V_{g}$ and does not depend 
on the contact area. It is possible that the conductive filaments in the insulator are a consequence of electroforming processes, the same as the formation of memristor cells. More likely, such defects begin from the boundary of the bonding interface, and that corresponds, in most cases, to leaks with a positive bias voltage $\mathrm{V}_{\mathrm{g}}$.

The buried insulator with amorphous $\mathrm{HfO}_{2}$ layers crystallizes at much lower temperatures $\mathrm{T} \sim 600-800{ }^{\circ} \mathrm{C}$ [16]. The hafnium dioxide band gap is also smaller than that of alumina, and it leads to an increase in the leakage currents in both furnace and rapid thermal annealing (RTA) (Figure 4). Reducing the leakages ensures the introduction of $\mathrm{Al}_{2} \mathrm{O}_{3}$ layers into the insulator based on hafnium dioxide. An increase in the thickness of aluminum oxide layer inserts by a factor of 5 reduces the leakage current by 4 orders of magnitude. However, in the case of $\mathrm{Al}_{2} \mathrm{O}_{3}$ contact with the silicon interface, the problem of built-in positive charge in the insulator arises again and, possibly, that of the formation of dipoles at $\mathrm{Al}_{2} \mathrm{O}_{3}$ or $\mathrm{HfO}_{2}$ heterointerfaces with $\mathrm{SiO}_{2}$ interlayers [28,29].

\subsection{Rectification and Hysteresis in the Symmetrical SIS with a $20 \mathrm{~nm}$ Stack $\mathrm{HfO}_{2} / \mathrm{Al}_{2} \mathrm{O}_{3} / \ldots / \mathrm{HfO}_{2}$}

The positive charge in the insulator still exists in the case of a symmetric arrangement of the $\mathrm{Al}_{2} \mathrm{O}_{3}$ insert inside the insulator as $\mathrm{HfO}_{2} / \mathrm{Al}_{2} \mathrm{O}_{3} / \mathrm{HfO}_{2}$, but oppositely directed dipoles compensate each other at the heterointerfaces (Figures 5a and 6a) [29]. The probability of dipole recharging can compensate the ferroelectric type hysteresis at the asymmetric n-SIS pseudo-MOSFET's drain-gate characteristics, but not for the symmetrical ones (Figures 6 and 7). These dipoles determine that "forward" and "reverse diode" characteristics of the leakage currents through the asymmetrical stack depend on their orientations (See Figure S2, Supplementary Materials). An increase in the total stack thickness to $30 \mathrm{~nm}$ decreases the gate leakage current $\mathrm{I}_{\mathrm{g}}$ by more than 2 orders of magnitude (see Figures S3 and S4, Supplementary Materials). At the same time, an increase in the furnace annealing temperature to $1000{ }^{\circ} \mathrm{C}$ does not lead to the essential increase in the gate leakage current $I_{g}$ due to the thick alumina insert in the high-k layer (Figure 6), but drastically decreases the IFS density and the hysteresis (Figure 5b). The $\mathrm{Al}_{2} \mathrm{O}_{3}$ insert inside the insulator demonstrates a low leakage current at voltages $\left|V_{g}\right|>1 \mathrm{~V}$ even after the furnace annealing at $1000{ }^{\circ} \mathrm{C}$, but without any hysteresis and dependence on the contact areas (Figures $5 \mathrm{~b}$ and $7 \mathrm{a}$ ). These defects still show the current rectification due to their different nature of both interfaces.

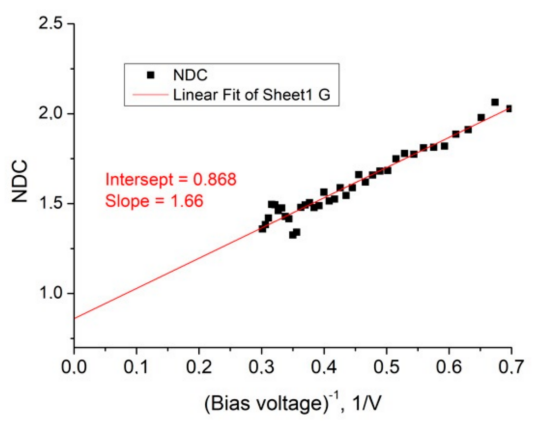

(a)

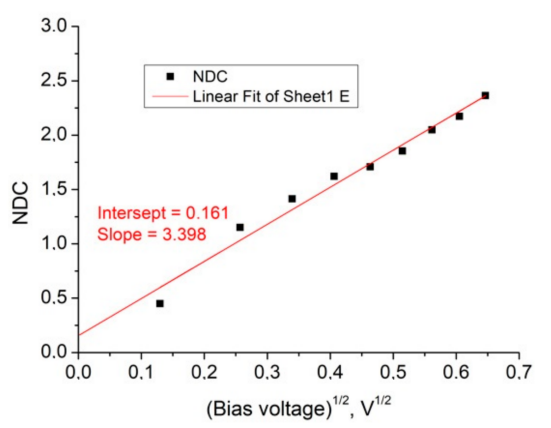

(b)

Figure 7. (a) Linear approximations of normalized differential conductance (NDC, according to [28], for the leakage current at the drain-gate contacts in the "forward" direction shown in the coordinates of $1 / \mathrm{V}$ for a larger bias voltage based on the data extracted from Figure S2; (b) the same in the $\mathrm{V}^{1 / 2}$ coordinates for a lower value of bias voltage.

To clarify the role of the near interface defects, the same structure was investigated with the special defect region in the n-Si substrate introduced by $\mathrm{CO}^{+}$ion implantation before the PEALD deposition and bonding (Figure 6b). Besides an increase in the leakage current, the polarity of the I-V branches was reversed by these defects near the bottom interface showing their role in the diode-like behavior. 


\section{Discussion}

\subsection{Random Shunts in the Built-in Insulator $\mathrm{HfO}_{2} / \mathrm{Al}_{2} \mathrm{O}_{3}$ Stacks}

The absence of $\mathrm{I}_{\mathrm{g}}$ dependence on the contact area ratio $\sim 13$ indicates the predominant contribution of "random" defects in oxide layer leakages after the annealing. It is important to note that this independence is observed for "reverse" current branches and that confirms their relation to the defects not only in the insulator, but also in the SCR. To verify the assumption of a connection of the diode-like behavior with the defects in the SCR, the electron distribution under the insulator after the RTA at $800{ }^{\circ} \mathrm{C}$ was measured by the $\mathrm{C}-\mathrm{V}$ method [29]. The high-resistance p- (i-) layer spreads the SCR in the substrate up to $2 \mu \mathrm{m}$ and ensures the constant $I_{g}$ leakage current value when the bias voltage $V_{g}$ changed in the interval of $+1-+8 \mathrm{~V}$ (Figure $7 \mathrm{~b}$ ). It can be seen that the contribution of nonlinear effects becomes dominating at the fields $\mathrm{E}>1 \mathrm{MV} / \mathrm{cm}$ that can be seen from the ratio of currents at lower voltages (Figure 4).

\subsection{Possible Mechanisms of the Charge Transport through Built-In Insulator $\mathrm{HfO}_{2} / \mathrm{Al}_{2} \mathrm{O}_{3}$ Stacks}

The $\mathrm{I}_{\mathrm{g}}$ currents in the forward direction through a thin insulator layer in the case of their significant (by 1-3 orders of magnitude) excess over the backward currents can be determined by a combination of several mechanisms at once: the resistive current through filaments/shunts in the dielectric, thermionic emission (TE) of charge carriers, direct interband tunneling, trap-assisted tunneling (TAT), emission from traps using the Poole-Frenkel (PF) mechanism, and the injection tunneling by Fowler-Nordheim (FN) mechanism. The relative contributions of these mechanisms depend on the layer thickness and electric field strength in the dielectric, as well as its temperature and defects, and can be extracted in various ways from the analysis of field and temperature dependences [30].

The space charge region in the SIS structures with the $\mathrm{CO}^{+}$implantation reduces the field in the dielectric layer due to the applied voltage redistribution between the depletion region and the built-in insulator of the structure, and that does not allow us to draw an unambiguous conclusion about the prevailing conduction mechanisms. Nevertheless, an estimate of the contribution of "random" defects to the leakage current can be obtained from a comparison of the I-V dependences for two different contacts on the same mesastructure. For instance, the leakage currents for Corbino n-type mesa structures on the $500 \mathrm{~nm}$ $\mathrm{n}-\mathrm{Si} / \mathrm{Al}_{2} \mathrm{O}_{3} 2 \mathrm{~nm} / \mathrm{HfO}_{2} 20 \mathrm{~nm} / \mathrm{Si}$ substrate through the insulator at the positive bias of $\mathrm{V}_{\mathrm{g}}>0.1 \mathrm{~V}$ (Figure S2) are caused after the RTA at $950{ }^{\circ} \mathrm{C}$ by the electron conductivity from the silicon film to the $\mathrm{Si}$ substrate through the oxide layer. The equivalent oxide thickness (EOT) of such BOX layer is about $5 \mathrm{~nm}$ in terms of $\mathrm{SiO}_{2}$. The currents in the forward direction exceed the currents in the backward direction by three orders of magnitude.

\subsection{Normalized Differential Conductance Approach for the Separation of Charge Transport Mechanisms}

Naturally, the analysis of normalized differential conductance (NDC) gives a better approximation of the linear dependence for high voltages (Figure 7a) for a "direct" drain current with a smaller area and, accordingly, with a lower probability of the contribution of random defects in two coordinates of the abscissa axis $1 / \mathrm{V}$ and $\mathrm{V}^{1 / 2}$ [30]. The intersection of the linear approximation with the ordinate axis at NDC $=0.9$ corresponds to the PooleFrenkel mechanism $(\mathrm{NDC}=1)$ for the electron transport through the built-in insulator (See Figure S4c,d, Supplementary Materials) [30,31]. The value NDC $=0.16$ for the $x$-axis in the $\mathrm{V}^{1 / 2}$ coordinates has an overestimated NDC value instead of the expected value $\mathrm{NDC}=0$, which corresponds to the thermionic emission of electrons at lower voltages $\mathrm{V}_{\mathrm{g}}$ (Figure $\mathrm{7b}$ ). A large error for lower $\mathrm{V}_{\mathrm{g}}$ values corresponds to a smaller fraction of nonlinear effects in the leakage current at low voltages. However, from the data in Figure 7, it follows that the dominant mechanism of the leakage current through the insulator layer from the high- $\mathrm{Al}_{2} \mathrm{O}_{3}(2 \mathrm{~nm}) / \mathrm{HfO}_{2}(20 \mathrm{~nm})$ stack without random defects is the thermionic emission at $0.15<\mathrm{V}_{\mathrm{g}}<0.9 \mathrm{~V}$ and the emission from traps by the Poole-Frenkel (PF) mechanism at $1.5<\mathrm{V}_{\mathrm{g}}<4.0 \mathrm{~V}$. The high leakage current in the forward direction at biasing 
$\mathrm{V}_{\mathrm{g}}>1 \mathrm{~V}$ show linear dependences with the slope $n=2$ in the log-log scale that corresponds to the Fouler-Nordheim tunneling mechanism in the high electric field E 1 MV/cm (See Figure S5, Supplementary Materials) [32].

The symmetrical n-SIS structures with the FE stack in the insulator can show diode like characteristics due to the insulator polarization at the coercive field $\mathrm{E}_{\mathrm{C}}$ (Figure 8). The observed asymmetry of the I-V characteristics of leakage currents through high-k dielectric stacks with an equivalent oxide thickness EOT 3-5 nm, even in the case of symmetrical structures of n-Si film $/ \mathrm{Al}_{2} \mathrm{O}_{3} / \mathrm{n}-\mathrm{Si}$ substrate, or n-Si film $/ \mathrm{HfO}_{2} / \mathrm{n}-\mathrm{Si}$ substrate, or $\mathrm{n}-\mathrm{Si}$ film $/ \mathrm{HfO}_{2} / \mathrm{Al}_{2} \mathrm{O}_{3} / \mathrm{HfO}_{2} / \mathrm{n}$-Si substrate could be explained by the unequal distribution of traps at the Si film/insulator and insulator/Si substrate hetero-interfaces, which differ in their formation (bonding and ALD deposition) technologies, as well as in terms of different concentrations of hydrogen atoms at the upper (bonding and hydrogen transfer processes) and lower (ALD deposition) heterointerfaces measured by the SIMS technique (Figure S4, Supplementary Materials). Hydrogen is involved in the oxygen vacancies formation and promotes the oxygen movement from the insulator layers to the boundaries with silicon. As a result, a thicker silicon oxide interlayer and a higher oxygen vacancies concentration in the insulator are formed at the upper boundary. The higher hydrogen content at the upper boundary corresponds to a high probability of detecting both random shunt defects with ohmic characteristics and direct quasi-diode characteristics with a rectification coefficient of up to $10^{2}$ at positive bias voltages on the substrate. The asymmetric structures of the n-Si film $/ \mathrm{HfO}_{2} / \mathrm{Al}_{2} \mathrm{O}_{3} / \mathrm{n}$-Si substrate and the n-Si film $/ \mathrm{Al}_{2} \mathrm{O}_{3} / \mathrm{HfO}_{2} / \mathrm{n}$-Si substrate demonstrate a 1-2 orders of magnitude higher rectification coefficient. At the same time, significantly higher $\mathrm{I}_{\mathrm{ds}}$ currents are observed at $\mathrm{V}_{\mathrm{g}} \sim 0$ Volt of the drain-gate characteristics of n-SIS pseudo-MOSFETs due to the large positive charge inside the insulator near the $\mathrm{n}-\mathrm{Si} / \mathrm{Al}_{2} \mathrm{O}_{3}$ heterointerfaces, which include the $\mathrm{SiO}_{2}$ interlayer, and a lower slope of characteristics due to the SCR additionally formed in the substrate by the $\mathrm{CO}^{+}$ion implantation (Figure 7). An SCR expansion using a $\mathrm{CO}^{+}$implanted getter also increases the rectification coefficient of these structures.

\subsection{Ferroelectricity in Nanolaminated Built-In Insulator $\mathrm{HfO}_{2} / \mathrm{Al}_{2} \mathrm{O}_{3} / \mathrm{HfO}_{2}$ Stacks}

The symmetrical SFS structures provide electrically switchable rectification due to the inherent switchable electric field. The band bending asymmetry, relative to the polarity of bias voltage, is demonstrated in Figure 8. This polarity depends on the up or down polarization even in the case of highly symmetric SIS structure. Moreover, the high remnant polarization $P_{r}$ provides a simultaneously strong accumulation and inversion at both interfaces in the slightly doped or undoped semiconductors. In other words, the ferroelectric polarization charges \pm Qr form the space charge region similar to the one in the $p-n$ junction if their charges are higher than those of trapped ones $\left|Q_{r}\right|>Q_{f}$.

The asymmetrical structures of the $\mathrm{n}-\mathrm{Si}$ film $/ \mathrm{HfO}_{2}: \mathrm{Al}_{2} \mathrm{O}_{3}(10: 1) / \mathrm{p}-\mathrm{Si}$ substrate (np-SFS) demonstrate, in addition to good insulating properties $\mathrm{I}_{\mathrm{g}}<10^{-7} \mathrm{~A} / \mathrm{cm}^{2}$ at $\left|\mathrm{V}_{\mathrm{g}}\right|<4 \mathrm{~V}$, a significant ferroelectric (FE) hysteresis, with a $\Delta \mathrm{V}_{\mathrm{g}} \sim 1.0-1.3 \mathrm{~V}$ memory window (MW) of the drain-gate characteristics of np-SIS pseudo-MOSFETs, as well as a saturated drain current $I_{d, s}$ (Figure 9). This current is saturated due to a long pseudoMOSFET channel with Schottky barrier contacts $[33,34]$. The voltage memory window $\Delta \mathrm{V}_{\mathrm{g}}$ is expressed through the FE remnant polarization $P_{r}$ as [16]:

$$
\Delta \mathrm{V}_{\mathrm{g}}=\mathrm{V}_{\mathrm{Tp}-}-\mathrm{V}_{\mathrm{Tp}^{+}}=2 \mathrm{P}_{\mathrm{r}} \varepsilon_{0} \varepsilon_{\mathrm{HAO}} / \delta,
$$

where $=V_{T p-}-V_{T p+}$ is the difference of the float band voltages for two polarizations and that coincides with the hole threshold voltage difference (see Figure S7, Supplementary Materials), $\delta$ is the distance between the charges in the FE insulator and in the channel $\sim 1 \mathrm{~nm}$. Equation (1) gives the value $2 \mathrm{P}_{\mathrm{r}}=23 \mu \mathrm{C} / \mathrm{cm}^{2}$, which corresponds to the published results for structures fabricated under similar conditions [35]. 

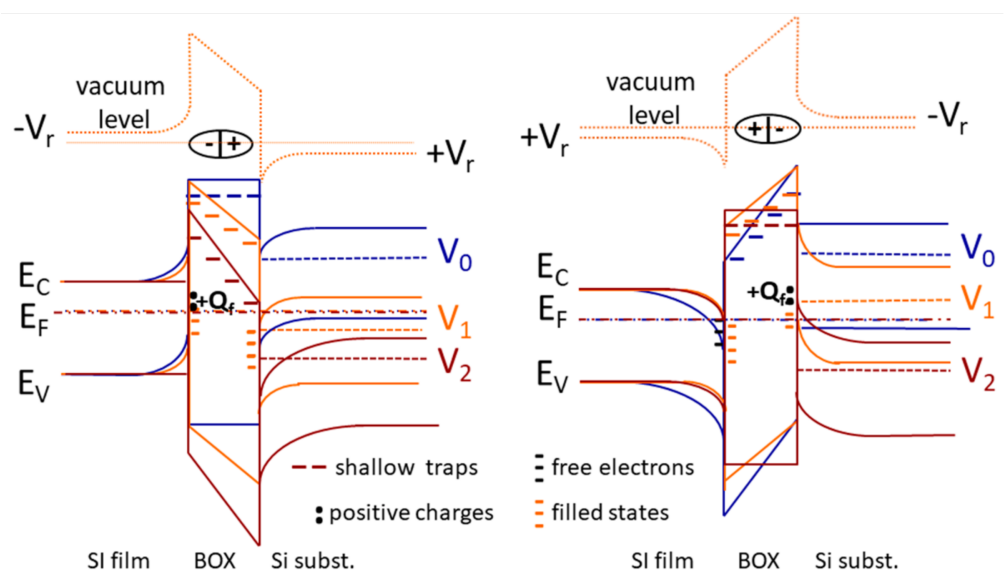

Figure 8. Silicon and hafnia bandgaps (not on the same energy scales for picture clarity) bending at the ferroelectric switching in the symmetric n-SIS structure with the two polarizations down to the substrates (left) and to the Si film (right), the shallow and deep electron traps with the $+Q_{f}$ net trapped charges at the boundaries of ferroelectric stack $\mathrm{HfO}_{2}: \mathrm{Al}_{2} \mathrm{O}_{3}$ (10:1) for the different $\mathrm{Si}$ substrate bias voltage $V_{\text {sub }}: V_{0}=-V_{R}$, where $V_{R}$ is the residual polarization voltage after/before the P-down switching (left), $V_{1}=0 \mathrm{~V}, \mathrm{~V}_{2}=\mathrm{V}_{\mathrm{R}}$, where $\mathrm{V}_{\mathrm{R}}$ is the voltage for the coercive switching of polarization (left). The same for the P-up switching in the built-in insulator (right). The Si film is grounded. The vacuum levels are shown for the $\mathrm{V}_{1}$ voltages only.

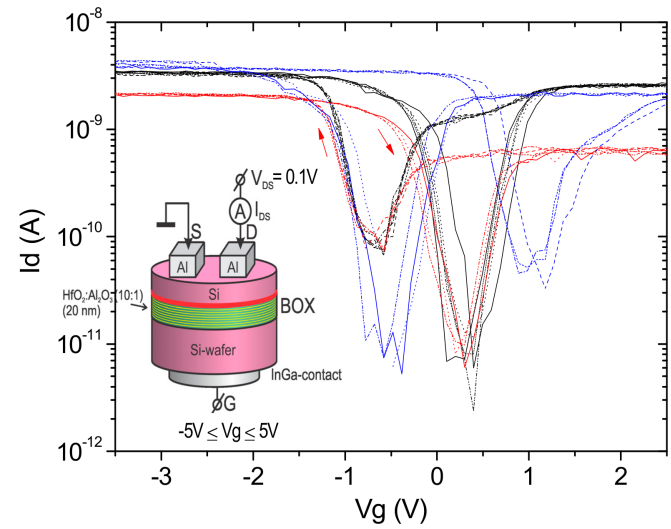

(a)

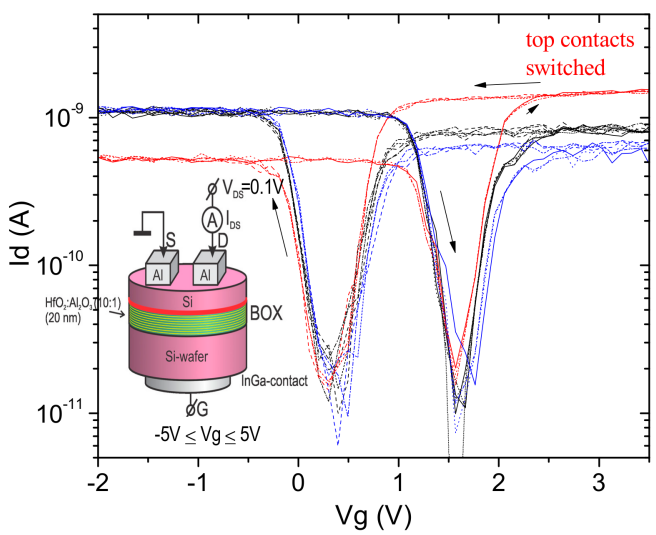

(b)

Figure 9. Ferroelectric hysteresis at the transfer characteristics of pseudo-MOSFET on the np-SIS mesastructure with the $500 \mathrm{~nm}$ n-Si/ $20 \mathrm{~nm}$ built-in insulator BOX nanolaminate $\mathrm{HfO}_{2}: \mathrm{Al}_{2} \mathrm{O}_{3}(10: 1) / \mathrm{n}-\mathrm{Si}$ substrate: (a) after the $\mathrm{RTA}$ at $800{ }^{\circ} \mathrm{C}$ and (b) after the RTA at $900{ }^{\circ} \mathrm{C}$ for three different sweep rates: $0.4 \mathrm{~V} / \mathrm{s}$ (black), $0.12 \mathrm{~V} / \mathrm{s}$ (red) and $0.04 \mathrm{~V} / \mathrm{s}$ (blue) and three sweep cycles (solid, dot and dash-dot lines).

The C-V, G-V and P-V loops, as well as the PUND pulse I-t measurements and PFM hysteresis, presented by Figures S8-S10 (Supplementary Materials) after the further RTA treatment at $950{ }^{\circ} \mathrm{C}$ confirm the ferroelectric nature of the transfer characteristic hysteresis in Figure 9. The last RTA treatment decreased the memory windows 3.7 times and that corresponds to the estimated value $2 \mathrm{P}_{\mathrm{r}} \sim 6 \mu \mathrm{C} / \mathrm{cm}^{2}$ (Figure S9a). Triangular pulses were applied to get the P-E hysteresis. The nonsymmetrical P-V loops with gaps are the result of reverse biasing in n-p SFS mesa structures. The PFM-V hysteresis is more symmetrical after n-Si layer removal (Figure S10b). 


\subsection{SFS Pseudo-MOSFET Characteristics}

The maximum mobility values for electrons and holes of SIS structures with the ferroelectric hysteresis were determined for pseudo-MOSFETs by the Y-function method according to the following formula [36]:

$$
\mu_{n, p}=\left(\beta_{n, p}\right)^{2} /\left(f_{n} C_{B O X} V_{D S}\right),
$$

where $\beta_{n, p}$ are the slopes of Y-function branches, $f_{n}=f_{p}=0.75$ or 5.3 is the geometric factor for two-probe measurements, or in Corbino geometry, respectively, $\mathrm{C}_{\mathrm{BOX}}$ is the buried oxide (BOX) capacity $\mathrm{C}_{\mathrm{BOX}}=\varepsilon_{0} \cdot \varepsilon_{\mathrm{BOX}} / \mathrm{t}_{\mathrm{BOX}}$ (dielectric constant $\left.\varepsilon_{\mathrm{BOX}} \sim 20\right), \mathrm{V}_{\mathrm{DS}}=0.1 \mathrm{~V}$ is the drain voltage.

The silicon layer mobility values $\mu$, determined from the maximum slopes of the linear branches of Y-functions (Figure 9), were $\mu_{\mathrm{n}}=120 \mathrm{~cm}^{2} /(\mathrm{V} \mathrm{s})$ and $\mu_{\mathrm{p}}=110 \mathrm{~cm}^{2} /(\mathrm{V} \mathrm{s})$ for electrons and holes, respectively. The density of states $D_{i t}$ were calculated using Equation (3) and the data (Figure S6b, Supplementary Materials), where there are only two linear segments on the Y-function branches:

$$
\mathrm{V}_{\mathrm{Tn}}-\mathrm{V}_{\mathrm{Tp}} \cong 2 \cdot \Phi_{\mathrm{F}}+\left(\mathrm{q} \cdot \mathrm{t}_{\mathrm{BOX}} / \varepsilon_{0} \cdot \varepsilon_{\mathrm{BOX}}\right) \cdot\left(\mathrm{N}_{0} \cdot \mathrm{t}_{\mathrm{Si}}+2 \cdot \Phi_{\mathrm{F}} \cdot \mathrm{D}_{\mathrm{it}}\right),
$$

where $\mathrm{q}$ is the electron charge, $\mathrm{N}_{0}$ is the donor concentration, $\Phi_{\mathrm{F}}=\mathrm{E}_{\mathrm{F}}-\mathrm{E}_{\mathrm{i}}=0.144 \mathrm{eV}$ is the Fermi level position in the silicon layer bulk with donor concentration $\mathrm{N}_{0}=410^{14} \mathrm{~cm}^{-3}$, $\mathrm{D}_{\mathrm{it}}$ is the density of states at the upper heterointerface and $\mathrm{t}_{\mathrm{Si}}$ is the top silicon layer thickness.

Then, according to the value of $\mathrm{V}_{\mathrm{Tn}}-\mathrm{V}_{\mathrm{Tp}}$ on the thickness of $\mathrm{t}_{\mathrm{BOX}}$ (Figure 9 and Figure S7) and Equation (2), the value of $D_{i t}=1.210^{11} \mathrm{~cm}^{-2}$ for the SFS with a $20 \mathrm{~nm}$ high-k stack of layered nanolaminate $\mathrm{HfO}_{2}: \mathrm{Al}_{2} \mathrm{O}_{3}$ (10:1). From these data, it can be concluded that the RTA treatments at $800{ }^{\circ} \mathrm{C}$ of the bonded silicon layer on the substrate with the hafnia-aluminabased nanolaminate built-in insulator provide the fabrication of Silicon-FerroelectricSilicon wafers with charge carrier mobility $\mu_{n, p}$ in the Si layer at levels of $\mu_{n}=120 \mathrm{~cm}^{2} /(\mathrm{V} \mathrm{s})$ and $\mu_{\mathrm{p}}=110 \mathrm{~cm}^{2} /(\mathrm{V} \mathrm{s})$ for electrons and holes, respectively (Figures 6a and 9). Keeping the carrier mobility and $\mathrm{FE}$ hysteresis after the rapid thermal annealing at $\mathrm{T} \sim 800{ }^{\circ} \mathrm{C}$ is required for optical SIS phase shifters, FeFET embedded nonvolatile memories and Siliconbased Associative Neural Network technologies compatible with the industrial CMOS approach $[10,13,37]$.

\section{Conclusions}

Investigations into the electrical characteristics of pseudo-MOSFETs mesa structures in n-SOI wafers were carried out with a $20 \mathrm{~nm}$ insulator with different high-k dielectrics layers-symmetric and asymmetrical stacks of the $\mathrm{Al}_{2} \mathrm{O}_{3} / \mathrm{HfO}_{2}$, and nanolaminate of $\mathrm{HfO}_{2}: \mathrm{Al}_{2} \mathrm{O}_{3}$-both in the two-probe measurement geometry and in Corbino geometry. The quasi-diode character of leakage currents through buried high-k built-in dielectrics with an equivalent oxide thickness EOT $=3-5 \mathrm{~nm}$ was detected, even in the case of symmetric semiconductor-insulator-semiconductor (SIS) structures with n-Si film $/ \mathrm{HfO}_{2} / \mathrm{Al}_{2} \mathrm{O}_{3} / \mathrm{HfO}_{2} / \mathrm{n}$-Si substrate. The reason for the diode-like characteristics in symmetrical SIS structures is explained by the asymmetry of the upper and lower heterointerfaces formed by the silicon bonding to the high-k insulating layer and ALD deposition of that layer on a silicon substrate, respectively. An additional factor is the different concentration of residual hydrogen at these interfaces, and it segregates in a subsequent SOI wafer annealing at $\mathrm{T}=800-1000{ }^{\circ} \mathrm{C}$. As a result, different spatial charge regions (SCRs) are formed near both $\mathrm{Si}$ /insulator interfaces.

The smallest leakage currents were obtained with high-k stacks containing an 8-10 nm $\mathrm{Al}_{2} \mathrm{O}_{3}$ layer, which also provided a barrier to the diffusion penetration of residual hydrogen into the substrate. In the SIS structures with the $\mathrm{Al}_{2} \mathrm{O}_{3} 2 \mathrm{~nm} / \mathrm{HfO}_{2} 20 \mathrm{~nm}$ stack and a rectification coefficient of $10^{3}$, it was shown that the dominant mechanism of electron transport through the dielectric at weak fields $\mathrm{E}<1 \mathrm{MV} / \mathrm{cm}$ is thermionic emission, and at 
large E values, the Poole-Frenkel (PF) mechanism of electron emission from traps in the insulator dominates.

The maximum carrier mobility $\mu=100-120 \mathrm{~cm}^{2} /(\mathrm{V}$ s) and the minimum density of states $D_{i t}=1.210^{11} \mathrm{~cm}^{-2}$ were obtained for the asymmetrical np-SIS structures with a high-k insulating stack of nanolaminate $\mathrm{HfO}_{2}: \mathrm{Al}_{2} \mathrm{O}_{3}(10: 1)$ after the RTA at $800{ }^{\circ} \mathrm{C}$. The FE hysteresis still remains with a memory window of MW $=1.0-1.3$ Volts at $0<\mathrm{V}_{\mathrm{g}}<3 \mathrm{~V}$ after the RTA processing of these SIS structures, and that makes it possible to use them as SFS substrates in the industrial CMOS process.

Silicon SIS structures with high-k stacks and nanolaminates of hafnia-alumina and bonded silicon layers of $\mathrm{n}$ - and $\mathrm{p}$-type conductivities are promising for optical phase shifters at reverse biases, as well as for their use in low-energy ICs, FeFET embedded nonvolatile memories and the Associative Neural Network circuitry due to the compatibility of such approach with the industrial CMOS technology and the preservation of the ferroelectric effect at the front-end-of-line CMOS processes, as we have shown it for the ferroelectric stack of $\mathrm{HfO}_{2}: \mathrm{Al}_{2} \mathrm{O}_{3}$ (10:1). The properties of the nonvolatile memory cells with FeFETs on the SFS substrates will be the goal of future research directions.

Supplementary Materials: The following are available online at https:/ /www.mdpi.com/2079-4 991/11/2/291/s1, Figure S1: Two SIS structure fabrication processes, Figure S2: Diode-like I-V curves at the source current-gate voltage. Figure S3: Diode-like I-V curves at the source current-gate voltage. Figure S4: SIMS atom distribution profile signals in the n-SIS structure. Figure S5: The I-V characteristics on the source-gate and drain-gate contacts of n-SIS pseudo-MOSFET structures in Corbino geometry, Figure S6: GIXRD spectra of the SFS sample, Figure S7: The Y-function for two sweep directions or the P-up and P-down polarisation, Figure S8: C-V characteristics on the sourcegate contacts of the n-p HAO SFS pseudo-MOSFET mesa structures, Figure S9.: P-V hysteresis for the n-p HAO SFS pseudo-MOSFET mesa structures, Figure S10: PFM Kelvin surface potential map.

Author Contributions: Conceptualization, V.P.P. and K.V.R.; methodology, V.P.P. and K.V.R.; software, V.A.A.; validation, V.P.P. and A.V.M.; formal analysis, F.V.T., S.G.S.; investigation, I.E.T., S.G.S., F.V.T. and V.A.A.; data curation, A.V.M.; writing — original draft preparation, V.P.P. and A.V.M.; writingreview and editing, V.P.P. and K.V.R.; visualization, A.V.M.; supervision, V.P.P.; project administration, V.P.P. and K.V.R.; funding acquisition, V.P.P. and I.E.T., All authors have read and agreed to the published version of the manuscript.

Funding: This research was funded by RFBR: grants no.18-42-540008 "Ferroelectric properties of metastable hafnium dioxide layers in SOS and SOI field-effect transistors", and no.19-29-03031 "Logic elements and architecture of information storage and processing chips with artificial intelligence based on two-gate ferroelectric transistors". The investigation was also partially supported by Research Program no. 066-2019-0004 of the Ministry of Science and Higher Education of Russia for Valiev Institute of Physics and Technology RAS.

Data Availability Statement: The data presented in this study are available on request from the corresponding author.

Acknowledgments: The authors thank E.V. Spesivtsev for his spectral ellipsometry measurements and A.A. Lomov for his glancing incidence X-ray diffraction (GIXRD) analysis of the ferroelectric stacks.

Conflicts of Interest: The authors declare no conflict of interest.

\section{References}

1. Kim, S.; Han, J.; Choi, W.J.; Song, J.D.; Kim, H.-J. Functionalized Bonding Materials and Interfaces for Heterogeneously LayerStacked Applications. J. Korean Phys. Soc. 2019, 74, 82-87. [CrossRef]

2. Li, E.; Zhou, B.; Bo, Y.; Wang, A.X. High-Speed Femto-Joule per Bit Silicon-Conductive Oxide Nanocavity Modulator. arXiv 2020, arXiv:2004.00983. [CrossRef]

3. Li, E.; Wang, A.X. High-Speed Atto-joule per Bit Photonic Crystal Nanocavity Modulator. In Proceedings of the 2019 IEEE Optical Interconnects Conference (OI), Santa Fe, NM, USA, 24-26 April 2019. 
4. Then, H.W.; Radosavljevic, M.; Jun, K.; Koirala, P.; Krist, B.; Talukdar, T.; Fischer, P. Gallium Nitride and Silicon Transistors on $300 \mathrm{~mm}$ Silicon Wafers Enabled by 3-D Monolithic Heterogeneous Integration. IEEE Trans. Electron Devices 2020, 67, 5306-5314. [CrossRef]

5. Zhao, Q.; Miao, J.; Zhou, S.; Gui, C.; Tang, B.; Liu, M.; Wan, H.; Hu, J. High-Power GaN-Based Vertical Light-Emitting Diodes on 4-Inch Silicon Substrate. Nanomaterials 2019, 9, 1178. [CrossRef] [PubMed]

6. Li, E.; Wang, A.X. Theoretical Analysis of Energy Efficiency and Bandwidth Limit of Silicon Photonic Modulators. J. Lightwave Technol. 2019, 37, 5801-5813. [CrossRef]

7. Harris, N.C.; Ma, Y.; Mower, J.; Baehr-Jones, T.; Englund, D.; Hochberg, M.; Galland, C. Compact and Low Loss Thermo-optic Phase Shifter in Silicon. Opt. Express 2014, 22, 10487-10493. [CrossRef] [PubMed]

8. Seok, T.J.; Quack, N.; Han, S.; Wu, M.C. Large-scale broadband digital silicon photonic switches with vertical adiabatic couplers. Optica 2016, 3, 64-70. [CrossRef]

9. Shen, Y.; Harris, N.; Skirlo, S.; Prabhu, M.; Baehr-Jones, T.; Hochberg, M.; Sun, X.; Zhao, S.; Larochelle, H.; Englund, D.; et al. Deep learning with coherent nanophotonic circuits. Nat. Photonics 2017, 11, 441. [CrossRef]

10. Saito, S.; Tomita, I.; Sotto, M.; Debnath, K.; Byers, J.; Al-Attili, A.Z.; Burt, D.; Husain, M.K.; Arimoto, H.; Ibukuro, K.; et al. Si photonic waveguides with broken symmetries: Applications from modulators to quantum simulations. Jpn. J. Appl. Phys. 2020, 59, SO0801. [CrossRef]

11. Han, J.; Bidenko, P.; Song, J.; Kim, S. Feasibility study on negative capacitance SIS phase shifter for low-power optical phase modulation. In Proceedings of the 2018 IEEE 15th International Conference on Group IV Photonics (GFP), Cancun, Mexico, 29-31 August 2018; pp. 39-40.

12. Han, J.-H.; Takenaka, M.; Takagi, S. Study on void reduction in direct wafer bonding using $\mathrm{Al}_{2} \mathrm{O}_{3} / \mathrm{HfO}_{2}$ bonding interface for high-performance Si high-k MOS optical modulators. Jpn. J. Appl. Phys. 2016, 55, 04EC06. [CrossRef]

13. Li, Q.; Ho, C.P.; Takagi, S.; Takenaka, M. Optical phase modulators based on reverse-biased III-v/si hybrid metal-oxidesemiconductor capacitors. IEEE Photonics Tech. Lett. 2020, 32, 345-348. [CrossRef]

14. Blom, P.W.M.; Wolf, R.M.; Cillessen, J.F.M.; Krijn, M.P.C.M. Ferroelectric Schottky diode. Phys. Rev. Lett. 1994, 73, $2107-2110$. [CrossRef] [PubMed]

15. Choi, T.; Lee, S.; Choi, Y.; Kiryukhin, V.; Cheong, S.-W. Switchable ferroelectric diode and photovoltaic effect in BiFeO 3 . Science 2009, 324, 63-66. [CrossRef] [PubMed]

16. Huang, B.C.; Chen, Y.T.; Chiu, Y.P.; Huang, Y.C.; Yang, J.C.; Chen, Y.C.; Chu, Y.H. Direct observation of ferroelectric polarizationmodulated band bending at oxide interfaces. Appl. Phys. Lett. 2012, 100, 122903. [CrossRef]

17. Xu, H.; Liu, Y.; Xu, B.; Xia, Y.; Wang, G.; Yin, J.; Liu, Z. Polarization-controlled tunable rectifying behaviors in highly oriented (K,Na) $\mathrm{NbO}_{3} / \mathrm{LaNiO}_{3}$ heterostructures on silicon. J. Phys. D Appl. Phys. 2016, 49, 375105. [CrossRef]

18. Dragoman, M.; Modreanu, M.; Povey, I.M.; Iordanescua, S.; Aldrigoa, M.; Dinescua, A.; Vasilachea, D.; Romanitan, C.; Dragoman, D. Current rectification effects in $6 \mathrm{~nm}$ thick $\mathrm{Hf}_{\mathrm{x}} \mathrm{Zr}_{1-\mathrm{x}} \mathrm{O}_{\mathrm{y}}$ ferroelectrics/Si planar heterostructures. Phys. E Low-Dimens. Syst. Nanostruct. 2018, 104, 241-246. [CrossRef]

19. Luo, Q.; Cheng, Y.; Yang, J.; Cao, R.; Ma, R.; Yang, Y.; Huang, R.; Wei, W.; Zheng, Y.; Gong, T.; et al. A highly CMOS compatible hafnia-based ferroelectric diode. Nat. Commun. 2020, 11, 1391. [CrossRef]

20. Schenk, T.; Pešić, M.; Slesazeck, S.; Schroeder, U.; Mikolajick, T. Memory technology-A primer for material scientists. Rep. Prog. Phys. 2020, 83, 086501. [CrossRef]

21. Sessi, V.; Simon, M.; Mulaosmanovic, H.; Pohl, D.; Loeffler, M.; Mauersberger, T.; Fengler, F.P.G.; Mittmann, T.; Richter, C.; Mikolajick, T.; et al. A Silicon Nanowire Ferroelectric Field-Effect Transistor. Adv. Electron. Mater. 2020, 6, 1901244. [CrossRef]

22. Zhou, Y.; Wang, C.; Tian, S.; Yaoa, X.; Gea, C.; Guoa, E.; Hea, M.; Yang, G.; Jin, K. Switchable ferroelectric diode and photovoltaic effects in polycrystalline BiFeO3 thin films grown on transparent substrates. Thin Solid Films 2020, 698, 137851. [CrossRef]

23. Tang, Y.-T.; Fan, C.-L.; Kao, Y.-C.; Modolo, N.; Cu, C.-J.; Kao, C.-H.; Wu, P.-J.; Hsaio, S.-W.; Yeh, W.-K.; Wang, Y.-H.; et al. A Comprehensive Kinetical Modeling of Polymorphic Phase Distribution of Ferroelectric-Dielectrics and Interfacial Energy Effects on Negative Capacitance FETs. In Proceedings of the 2019 Symposium on VLSI Technology, Kyoto, Japan, 9-14 June 2019; pp. T222-T223.

24. Tyschenko, I.E.; Popov, V.P. Silicon-on-insulator structures produced by ion-beam synthesis and hydrogen transfer. In Advances in Semiconductor Nanostructures; Latyshev, A.V., Dvurechenskii, A.V., Aseev, A.L., Eds.; Elsevier: Amsterdam, The Netherlands, 2017; pp. 409-436. ISBN 978-0-12-810512-2.

25. Popov, V.P.; Antonov, V.A.; Tyschenko, I.E.; Vdovin, V.I.; Gutakovskii, A.K.; Miakonkikh, A.V.; Rudenko, K.V. Hafnia and alumina stacks as UTBOXs in silicon-on insulator structures. Solid State Electron. 2020, 168, 107734. [CrossRef]

26. Popov, V.P.; Antonov, V.A.; Vdovin, V.I. Positive Charge in SOS Heterostructures with Interlayer Silicon Oxide. Semiconductors. Semiconductors 2018, 52, 1341-1348. [CrossRef]

27. Popov, V.; Ilnitsky, M.; Antonov, V.; Vdovin, V.; Tyschenko, I.; Miakonkikh, A.; Rudenko, K. Ferroelectric properties of SOS and SOI pseudo-MOSFETs with $\mathrm{HfO}_{2}$ interlayers. Solid-State Electron. 2019, 159, 63-70. [CrossRef]

28. Hotta, Y.; Kawayama, I.; Miyake, S.; Saiki, I.; Nishi, S.; Yamahara, K.; Arafune, K.; Yoshida, H.; Satoh, S.; Sawamoto, N.; et al. Control of dipole properties in high-k and $\mathrm{SiO}_{2}$ stacks on $\mathrm{Si}$ substrates with tricolor superstructure. Appl. Phys. Lett. 2018, 113, 012103. [CrossRef] 
29. Popov, V.; Antonov, V.; Tikhonenko, F.; Miakonkikh, A.; Simakin, S.; Rudenko, K.; Lukichev, V. Modifying SOI Properties by the $\mathrm{CO}^{+}$Molecular Ion Implantation. In EUROSOI-ULIS 2020; IEEE Express: Caen, France, 2020; in press.

30. Ortiz-Conde, A.; Sucre-González, A.; Torres-Torres, R.; Molina, J.; Murphy-Arteaga, R.S.; García-Sánchez, F.J. Conductance-toCurrent-Ratio-Based Parameter Extraction in MOS Leakage Current Models. IEEE Trans. Electron Devices 2016, 63, 3844-3850. [CrossRef]

31. Nouibat, T.H.; Messai, Z.; Chikouch, D.; Ouennoughi, Z.; Rouag, N.; Rommel, M.; Frey, L. Normalized differential conductance to study current conduction mechanisms in MOS structures. Microelectron. Reliab. 2018, 91, 183-187. [CrossRef]

32. Ranuárez, J.C.; Deen, M.J.; Chen, C.-H. A review of gate tunneling current in MOS devices. Microelectron. Reliab. 2006, 46, 1939-1956. [CrossRef]

33. Yojo, L.S.; Rangel, R.C.; Sasaki, K.R.A.; Martino, J.A. Analytical modeling of the p-type BESOI MOSFET at linear region operation. In Proceedings of the 2019 34th Symposium on Microelectronics Technology and Devices (SBMicro), Sao Paulo, Brazil, 26-30 August 2019.

34. Yojo, L.S.; Rangel, R.C.; Sasaki, K.R.A.; Ortiz-Conde, A.; Martino, J.A. Impact of Schottky contacts on p-type back enhanced SOI MOSFETs. Solid-State Electron. 2020, 169, 107815. [CrossRef]

35. Liu, X.; Yao, L.; Cheng, Y.; Xiao, B.; Liu, M.; Wang, W. Observing large ferroelectric polarization in top-electrode-free $\mathrm{Al}_{\text {:HfO }} 2$ thin films with Al-rich strip structures. Appl. Phys. Lett. 2019, 115, 152901. [CrossRef]

36. Cristoloveanu, S.; Ionica, I.; Diab, A.; Liu, F. The pseudo-MOSFET: Principles and recent trends. ECS Trans. 2012, 50, 249-258. [CrossRef]

37. Tarkov, M.S.; Leushin, A.N.; Tikhonenko, F.V.; Tyschenko, I.E.; Popov, V.P. Logic Elements and Crossbar Architecture Based on SOI Two-Gate Ferroelectric Transistors. In EUROSOI-ULIS 2020; IEEE Express: Caen, France, 2020; in press. 